\title{
Survey of rice storage facilities identifies research and education needs
}

by Luis A. Espino, Chris A. Greer, Randall G. Mutters and James F. Thompson

More than 40 million hundredweights of rice are produced in California's Sacramento Valley every year. After harvest, the rice is stored in facilities on-farm or off-farm until it is transported to mills or to ports for export. We conducted a survey of storage operations to characterize grain storage and pest management practices to guide future UC Cooperative Extension research efforts. The results indicate that grain moisture content, temperature and insect pest management are the most important challenges for both on- and off-farm storage operations. Survey responses show high adoption of integrated pest management programs, with most storage operations relying on monitoring, thresholds, sanitation and aeration to manage pest problems. Fumigant use was reported more frequently in off-farm storage operations than on-farm operations. Cooperative Extension educational efforts should focus on grain and temperature monitoring, insect identification and safe use of fumigants. Research is needed to improve management of grain temperature and moisture content, and insect infestations.

R ice is one of the most important crops in California's Sacramento Valley. Approximately 500,000 acres are planted annually (Hill et al. 2006). From 2000 to 2011, California produced an average of 43.4 million hundredweights (cwt, $1 \mathrm{cwt}=100$ pounds) of rough rice (unprocessed rice that includes hull and caryopsis) per year. After harvest, rice is dried and stored either on-farm or at commercial drying and storage facilities off-farm. Rice is typically harvested when grain moisture content is between $18 \%$ and $22 \%$. To preserve its quality and allow long-term storage, rice needs to be dried down to $13 \%$ to $14 \%$

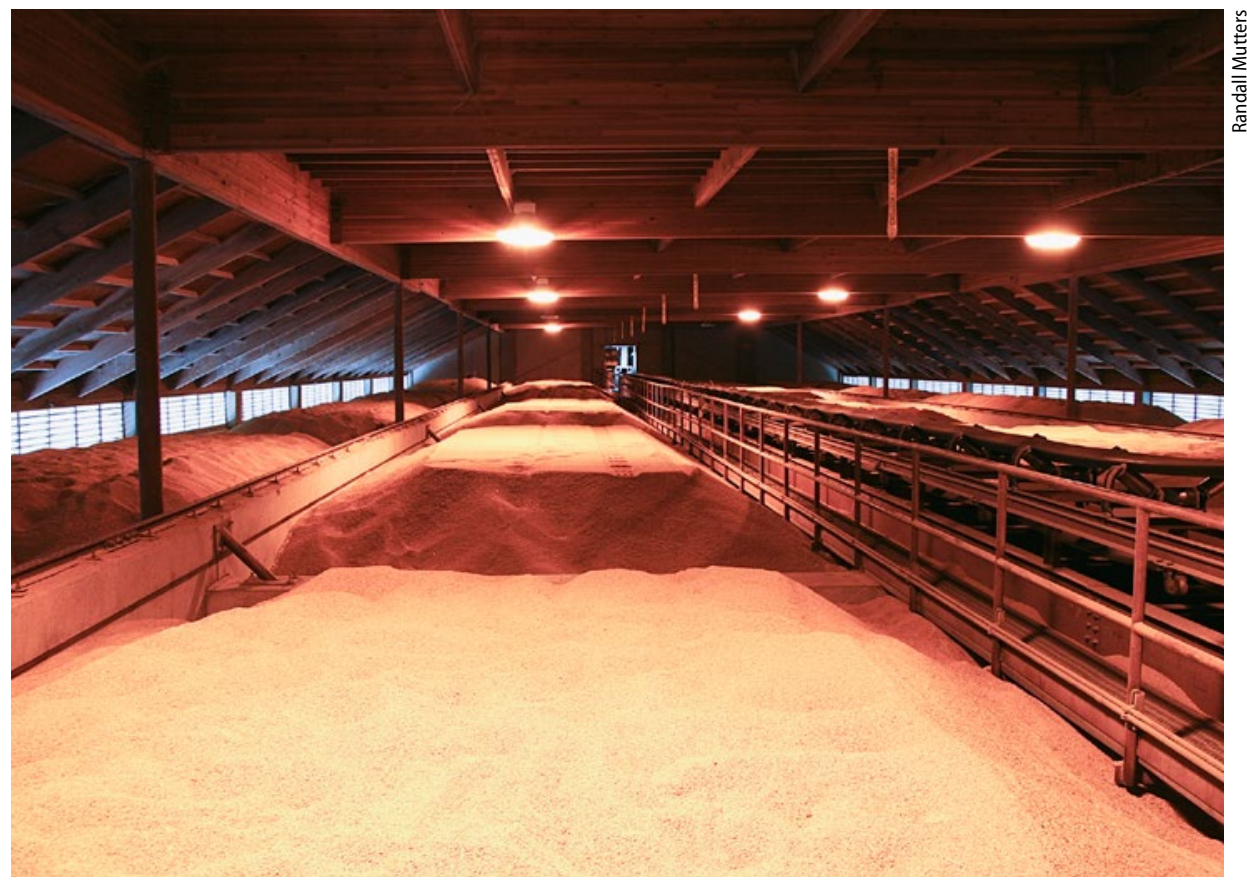

A UC Cooperative Extension survey of stored-rice management practices in California's major riceproducing counties found that keeping rice at the appropriate moisture content and temperature and free of insect infestations are the most important challenges operators face.

moisture content (Mutters and Thompson 2009).

Most on-farm storage facilities use metal bins of various capacities for drying and storage; the rice is dried using outside air. Off-farm storage facilities use column dryers to dry rice to $16 \%$ or $17 \%$ moisture content and finish the drying in storage structures using outside air (Kunze and Calderwood 1985; Mutters and Thompson 2009). In some cases, large farming operations own a column dryer and receive rice from other farmers for drying and storage.

California rice is stored as rough rice until it is shipped for milling. Rice needs to be maintained at an appropriate temperature and moisture content to preserve its quality. In addition, it needs to be protected from damage by insects and other pests, such as rodents and birds. Insect infestation during storage can reduce the selling price by negatively affecting the rice grade, determined by the percentage of insect-damaged kernels, or by causing the rice to be classified as "infested" if live insects are found in a sample (USDA FGIS 2002). Insect activity can also increase grain temperature and promote the growth of microorganisms that cause spoilage and reduce the quality of the rice. High grain temperatures and moisture may also cause odors that further reduce the value of the rice.

Fumigants are commonly used to prevent or eliminate insect infestations during rice storage. During 2010, 8.5 million cwt of rice were fumigated in California, using 12,327 pounds of fumigant active ingredients (DPR 2011). Prior to our survey, the extent to which other management practices, such as monitoring, sanitation and aeration, are used in stored rice was unknown.

To determine how the industry manages the storage of rough rice and its use of integrated pest management (IPM), we conducted a mail survey of rice producers and commercial facilities that store rough rice. We collected baseline information regarding storage infrastructure, grain and pest management practices and economic impacts of pest problems. Our goal was to gather information that would help

Online: http://californiaagriculture.ucanr.edu/ landingpage.cfm?article=ca.v068n01p38\&fulltext=yes doi: 10.3733/ca.v068n01p38 


\begin{tabular}{|c|c|c|c|c|c|c|c|c|}
\hline \multirow[b]{2}{*}{ County } & \multicolumn{5}{|c|}{ On-farm operations } & \multicolumn{3}{|c|}{ Off-farm operations } \\
\hline & $n$ & $\begin{array}{l}\text { Survey-reported } \\
\text { acreage }\end{array}$ & $\begin{array}{l}\% \text { of } 2010 \text { county } \\
\text { harvested acreage }\end{array}$ & $\begin{array}{l}\text { Survey-reported } \\
\text { stored rice }\end{array}$ & $\begin{array}{l}\% \text { of } 2010 \text { county } \\
\text { production }\end{array}$ & $n$ & $\begin{array}{l}\text { Survey-reported } \\
\text { stored rice }\end{array}$ & $\begin{array}{l}\% \text { of } 2010 \text { county } \\
\text { production }\end{array}$ \\
\hline & & acres & $\%$ & $c w t$ & $\%$ & & $c w t$ & $\%$ \\
\hline Butte & 1 & 273 & 0.29 & 3,000 & 0.04 & 4 & $5,544,000$ & 69.53 \\
\hline Colusa & 11 & 10,810 & 7.13 & 544,650 & 4.48 & 12 & $7,406,522$ & 60.96 \\
\hline Glenn & 12 & 9,017 & 10.62 & 551,400 & 8.41 & 1 & 923,000 & 14.07 \\
\hline Sutter & 5 & 3,860 & 3.37 & 415,000 & 4.51 & 7 & $5,536,307$ & 60.18 \\
\hline Yolo & 1 & 4,200 & 10.34 & 95,424 & 3.03 & 5 & $5,618,000$ & 178.35 \\
\hline Yuba & 1 & 281 & 0.73 & 74,408 & 2.46 & 0 & - & - \\
\hline Statewide & 31 & 28,441 & 5.14 & $1,683,882$ & 3.80 & 29 & $25,027,829$ & 56.46 \\
\hline
\end{tabular}

* Source: USDA NASS 2012.

determine UC research and Cooperative Extension education priorities for storedrice management in California.

\section{Survey}

Contact information for rice growers who have on-farm storage facilities was obtained from UC Cooperative Extension farm advisors and county agricultural commissioner's offices in the major riceproducing counties of California. Contact information for commercial rice dryers and warehouses was obtained from the 2009-2010 California Warehouse Association directory. A draft questionnaire was circulated among a small subset of representative storage operators and UC personnel familiar with the industry to improve the clarity and relevance of the questions. Once finalized, the questionnaire consisted of a 10-page booklet that included instructions, 29 questions and space for comments (see sample questionnaire at http://ucanr.edu/u.cfm?id=88). The instructions directed respondents to answer the questions based on their experiences during the 2010-2011 storage period (storage of the 2010 harvest) unless otherwise indicated in the question.

The survey protocol was approved by the UC Davis Institutional Review Board. Survey implementation followed the recommendations of Dillman et al. (2009). Briefly, pre-notice letters informing recipients that they would be receiving a survey were mailed to 134 contacts on Jan. 3, 2012. Detailed letters explaining the objectives of the survey, questionnaires and pre-stamped, self-addressed return envelopes were mailed on Jan. 6. Thank you/reminder postcards were mailed on Jan. 17. Reminder letters, questionnaires and pre-stamped, self-addressed return envelopes were mailed on Feb. 3 to contacts who had not returned the questionnaire by that date.

Of the 134 contacts, 10 returned the survey noting that they did not store rice and 8 surveys were returned by the U.S. Postal Service as undeliverable. As a result, surveys were received by 116 valid contacts. Of these, 61 returned completed questionnaires between January and April, a return rate of $53 \%$. Not all respondents answered all the questions; the number of respondents for each question is indicated in the results.

Respondents who reported farming rice and using on-farm storage bins but not owning a column dryer were classified as on-farm storage operations; respondents who reported not farming rice were classified as off-farm storage operations. Respondents who reported farming rice and owning a column dryer were classified as on-farm operations if they stored no more than $125 \%$ of their production potential, calculated as acreage reported times $80.2 \mathrm{cwt}$, the average rice yield per acre in California for 2010 (USDA NASS 2012); otherwise, they were classified as off-farm operations.

Responses were received from all major rice-producing counties of California (table 1). The sum of all rice acreage and storage reported by on-farm operations represents a small fraction of the total acreage and rice produced in California in 2010. The sum of all rice stored reported by off-farm operations represents more than half of 2010 California rice production.

The amount of rice stored per operation varied greatly. On average, on-farm operations $(n=28)$ reported storing 60,100 cwt of rice. The quantities stored ranged from 3,000 to 230,000 cwt. Off-farm operations $(n=26)$ reported storing between 65,000 and 4.1 million cwt of rice, with an average of $962,600 \mathrm{cwt}$.

Total on- and off-farm stored rough rice reported in the survey represented $60 \%$ and $69 \%$, respectively, of the USDA's

\begin{tabular}{|c|c|c|c|c|c|c|}
\hline \multirow[b]{2}{*}{ Structure type } & \multicolumn{3}{|c|}{ On-farm operations $(n=32)$} & \multicolumn{3}{|c|}{ Off-farm operations $(n=29)$} \\
\hline & Number & Total capacity & Total rice stored & Number & Total capacity & Total rice stored \\
\hline & \multicolumn{3}{|c|}{$\ldots \ldots \ldots \ldots \ldots$ cwt $\ldots \ldots \ldots \ldots \ldots$} & \multicolumn{3}{|c|}{ 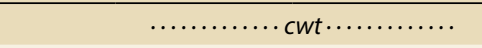 } \\
\hline Round metal bins & 10 & 64,105 & 56,129 & 25 & 337,698 & 300,941 \\
\hline Concrete silos & 0 & 0 & 0 & 17 & 185,796 & 168,896 \\
\hline Flat warehouses & 0 & 0 & 0 & 2 & 532,798 & 519,238 \\
\hline
\end{tabular}




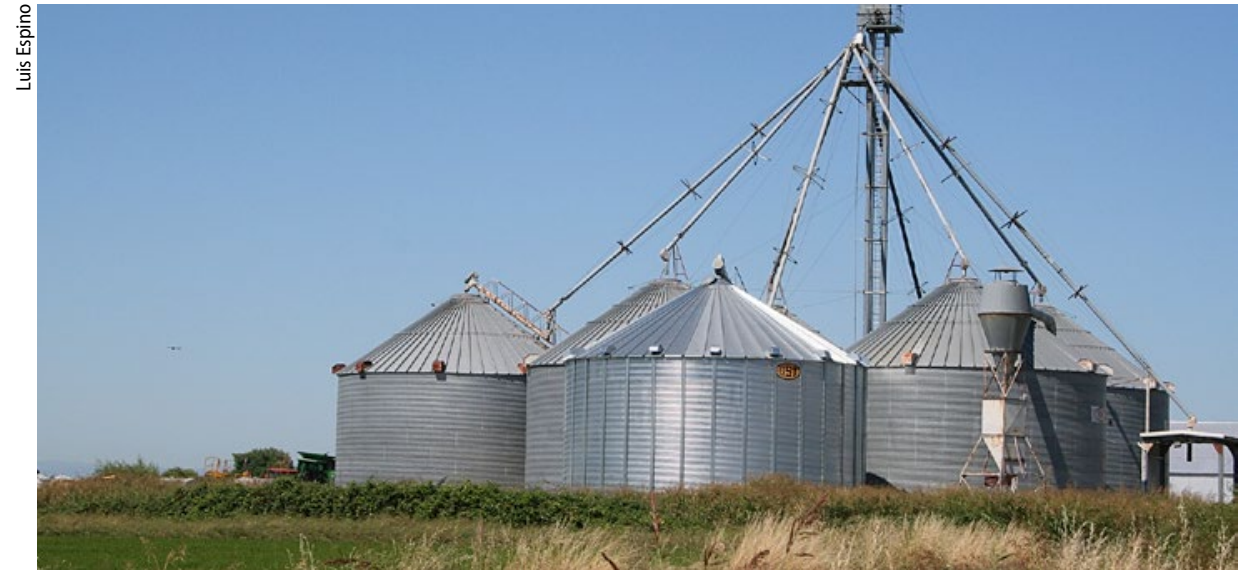

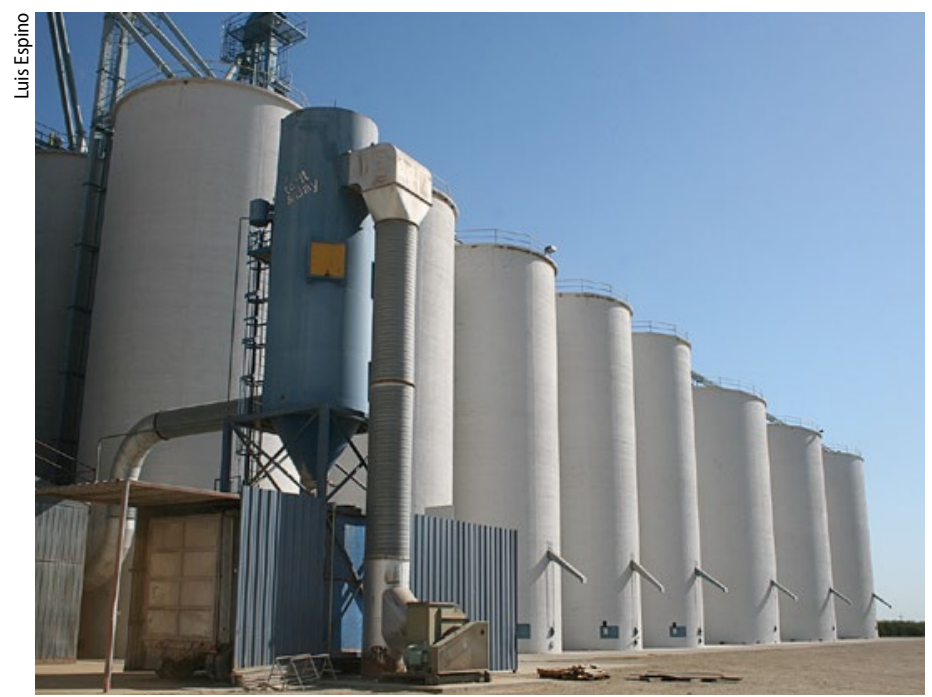
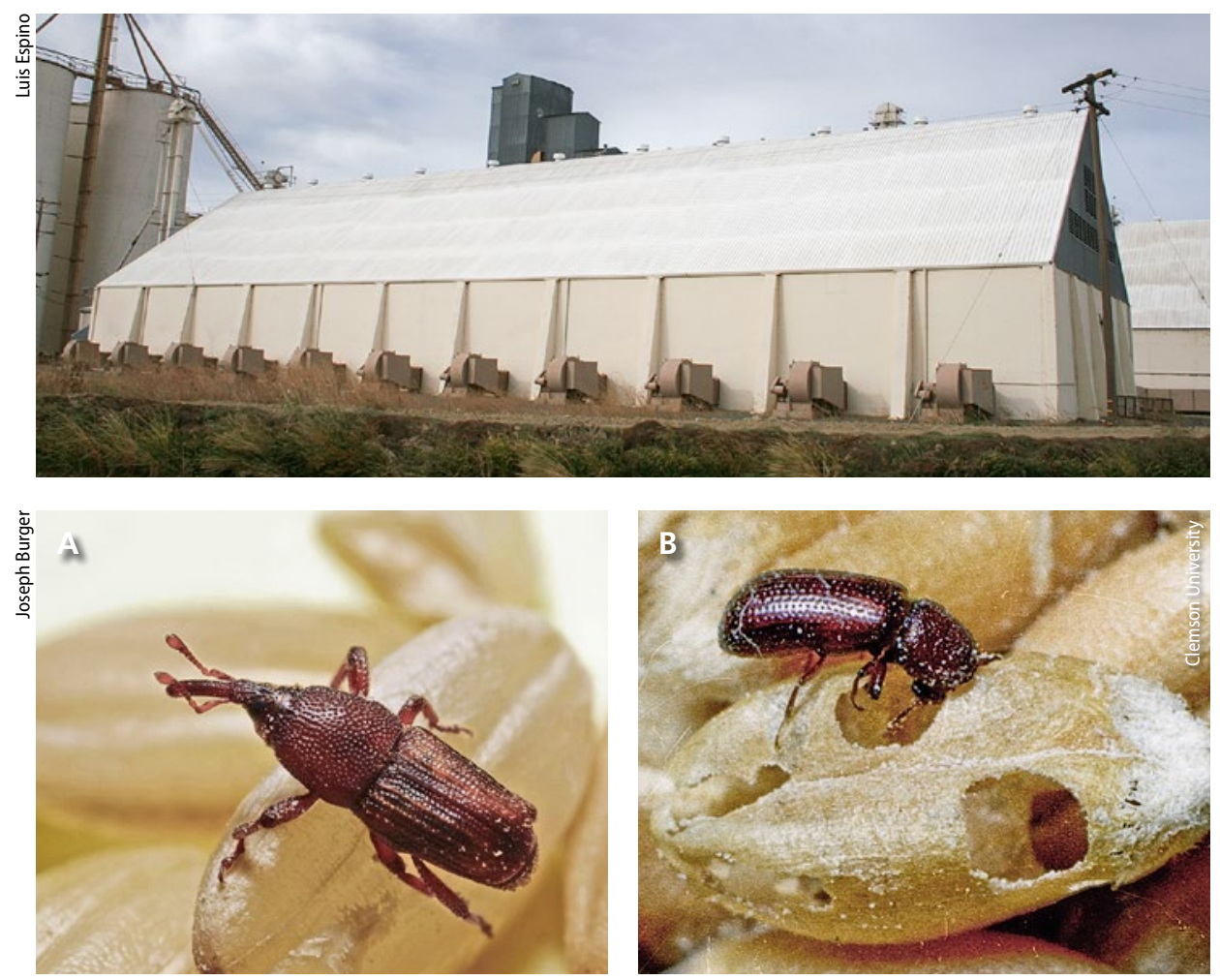

In California, after harvest, rice is stored in metal bins, top; concrete silos, middle; and flat warehouses, bottom. Round metal bins are typical in on-farm storage operations, while all three structures are common in off-farm operations. During the 2010-2011 storage period, onand off-farm storage operations used on average $81.6 \%$ and $89.5 \%$, respectively, of their storage capacity.

The rice weevil (A), lesser grain borer $(B)$ and red flour beetle $(C)$ were selected by the majority of survey respondents as insects causing problems in stored rice. estimate (USDA NASS 2012) of rough rice stored on- and off-farm by Dec. 1, 2010, respectively, demonstrating that our survey included operations that account for a large proportion of the rice stored in the Sacramento Valley.

\section{Storage structures, systems}

Three types of structures are used in California to store rice: metal bins, concrete silos and flat warehouses. After harvest, rice may be put in bins and dried using outside air. This type of drying, known as bin drying, is widely used by on-farm operations (Kunze and Calderwood 1985). Alternatively, rice can be dried by using heated air first, followed by ambient air. Using a column dryer, rice is dried to $16 \%$ or $17 \%$ moisture content and then transferred to bins, silos or flat warehouses, where the drying process continues, with outside air, to achieve the final $14 \%$ moisture content. This combination system is typically used by commercial rice dryers in California (Kunze and Calderwood 1985).

The main structure type used by onfarm storage operations that responded to the survey is round metal bins (table 2). Off-farm operations reported round metal bins, concrete silos and flat warehouses. During the 2010-2011 storage period, onand off-farm storage operations used on average $81.6 \%$ and $89.5 \%$, respectively, of their storage capacity

To preserve the quality of rice during storage, managers need to keep it at an appropriate temperature and moisture content. For this, outside air is regularly forced through the grain mass. The decision to aerate is based on the temperature and moisture content of the grain (Mutters and Thompson 2009; Steffe et al. 1980). Managers start or stop

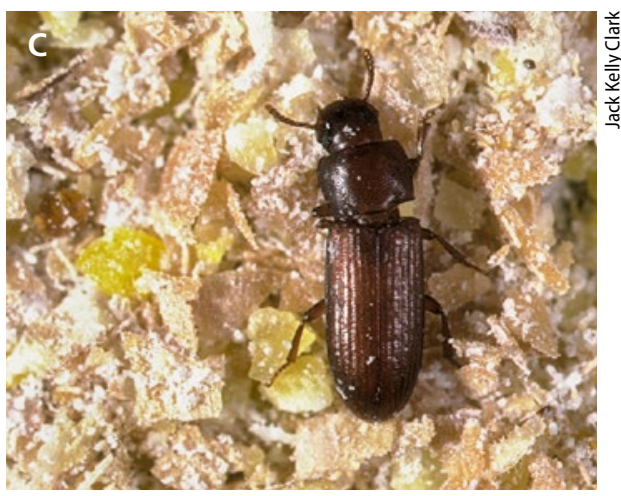


fans manually when conditions are appropriate to dry and maintain rice at the desired temperature and moisture content. Alternatively, an aeration controller system can be used to automatically start and stop fans. Our survey shows that aeration controller systems are uncommon. Only one on-farm and eight off-farm operations reported having an aeration controller system.

Grain temperature can be assessed using hand-held thermometers, temperature probes or temperature cables. Hand-held thermometers can measure the temperature of the grain mass surface or of a sample extracted from the grain mass using a grain probe. Temperature probes can be inserted into the grain mass to determine the temperature of the grain at a certain depth. Temperature cables are sensors suspended from the roof of a storage structure that run nearly to the floor of the structure; the number of cables in a structure varies with the structure's size. Temperature probes and cables allow managers to detect grain temperature changes at different grain depths without having to extract samples from these depths. Most of the operations replying to our survey report monitoring grain temperature during storage (see below, "Aeration"). The majority of on-farm operations $(n=23)$ report using a hand-held thermometer $(52.2 \%)$, while most off-farm operations $(n=24)$ report relying on temperature cables within storage structures $(79.2 \%)$.

\section{Storage problems}

Survey respondents were asked to choose and rank the three most important rough rice storage problems they experienced during the past 5 years from a list of six potential problems (fig. 1). For each respondent, the problem ranked as most important, second most important, and third most important received a score of 3,2 and 1, respectively, and problems that were not ranked received a score of 0 . Then, for each problem, the average and relative scores were calculated. A problem's relative score was determined by dividing the problem's average score by the highest possible average score (3). For onfarm operations, maintaining appropriate grain moisture is one of the most important problems respondents faced, followed by insects and grain temperature. For off-farm operations, one of the most

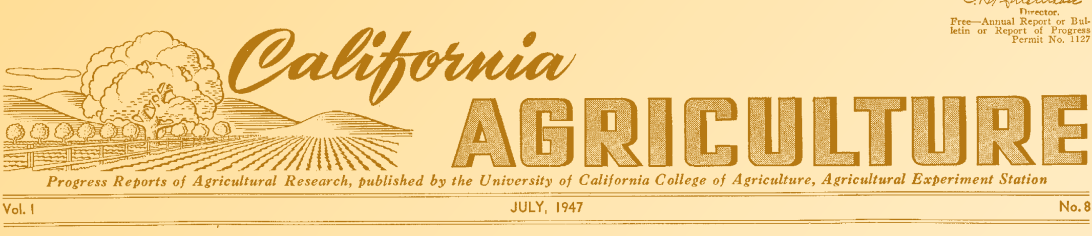

\section{Early grain storage research}

1947 "Many insects that infest grain in farm storage are small. Some are smaller than a grain of wheat. In fact, with some species, a single kernel of grain furnishes sufficient food for the development of from one to several individuals.

"Among the more important pests are the granary weevil, rice weevil, lesser grain borer, Angoumois grain moth, confused flour beetle and the sawtoothed grain beetle. The first four mentioned are capable of attacking and destroying sound grain. The others generally feed upon broken grains, particularly the finer particles.

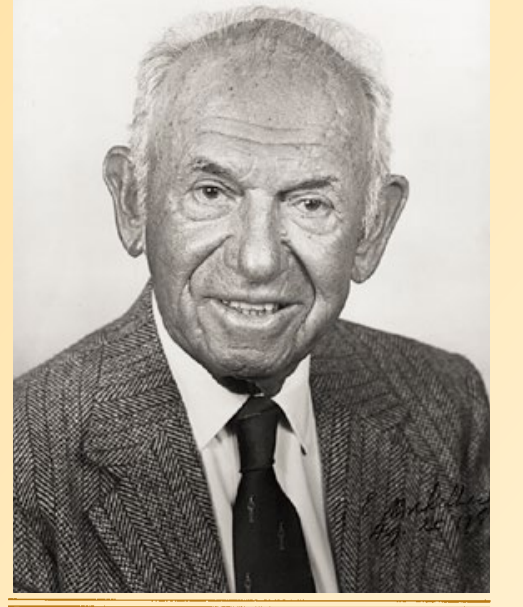

Dryness Protects Farm Stored Grain From Insect Attack

\section{A. E. Michelbacher}

Many insects that infest grain in farm storage are small. Some are smaller than a grain of wheat. In fact, with some species, a single kernel of grain furnishes sufficient food for the development of from one to several individuals.

Among the more important pests are the granary weevil, rice weevil, lesser grain borer, Angoumois grain moth, confused flour beetle and the saw-toothed grain beetle. The first four mentioned are capable of attacking and destroying sound grain. The others generally feed upon broken grains, particularly the finer particles.

Where the environment is favorable, these insects cause serious damage and under extreme conditions the grain may be completely destroyed. Most of the important grain pests are wide-spread throughout California and if grain is not properly protected it is subject to heavy infestation.

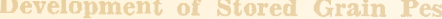

"Where the environment is favorable, these insects cause serious damage and under extreme conditions the grain may be completely destroyed. Most of the important grain pests are widespread throughout California and if grain is not properly protected it is subject to heavy infestation.

"The development of stored grain pests is largely regulated by temperature and the moisture content of the food on which they feed. The most favorable temperature range is from 80 to 85 Deg. F; while the most ideal moisture content of the food ranges from 13 to 17 per cent."

At the time of this writing, author Abraham E. Michelbacher was assistant professor of entomology and assistant entomologist at the Agricultural Experiment Station at UC Berkeley. He went on to become a full professor and leader in UC Berkeley's Department of Entomology, as well as a pioneer in the fields of biological pest control and the specifically targeted use of pesticides. After retirement in 1960, he was named professor emeritus and continued his research and Extension work for nearly 30 years more. Michelbacher died in 1991, aged 92.

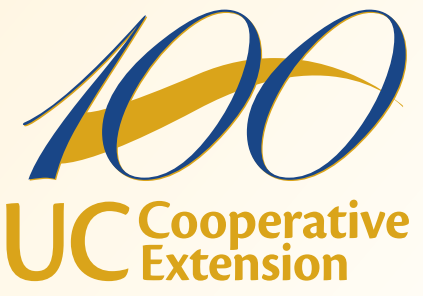

A Celebration of Science and Service 


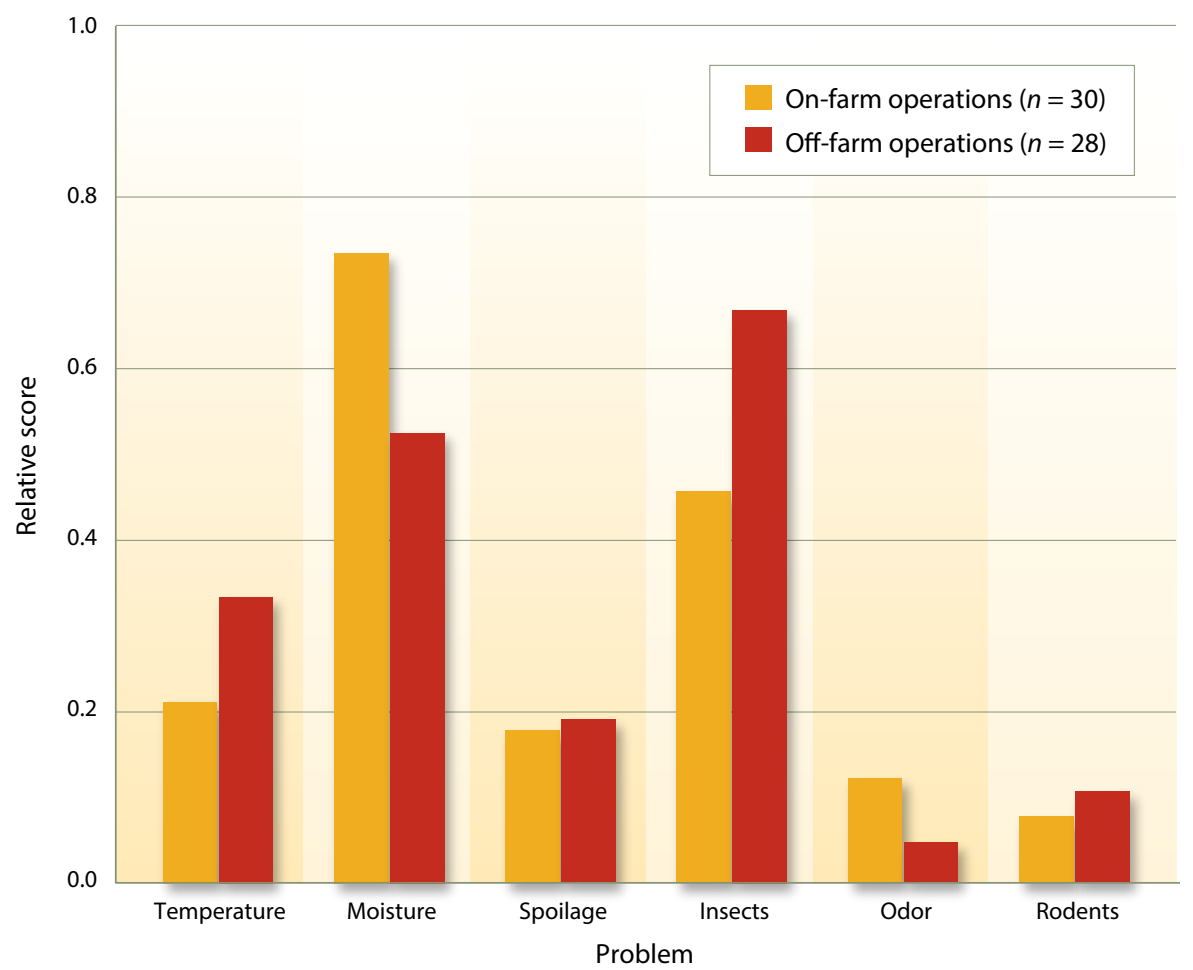

Fig. 1. Relative score of problems important to rice storage operations in the past 5 years. A problem's relative score was determined by dividing the problem's average score by the highest possible average score (3).

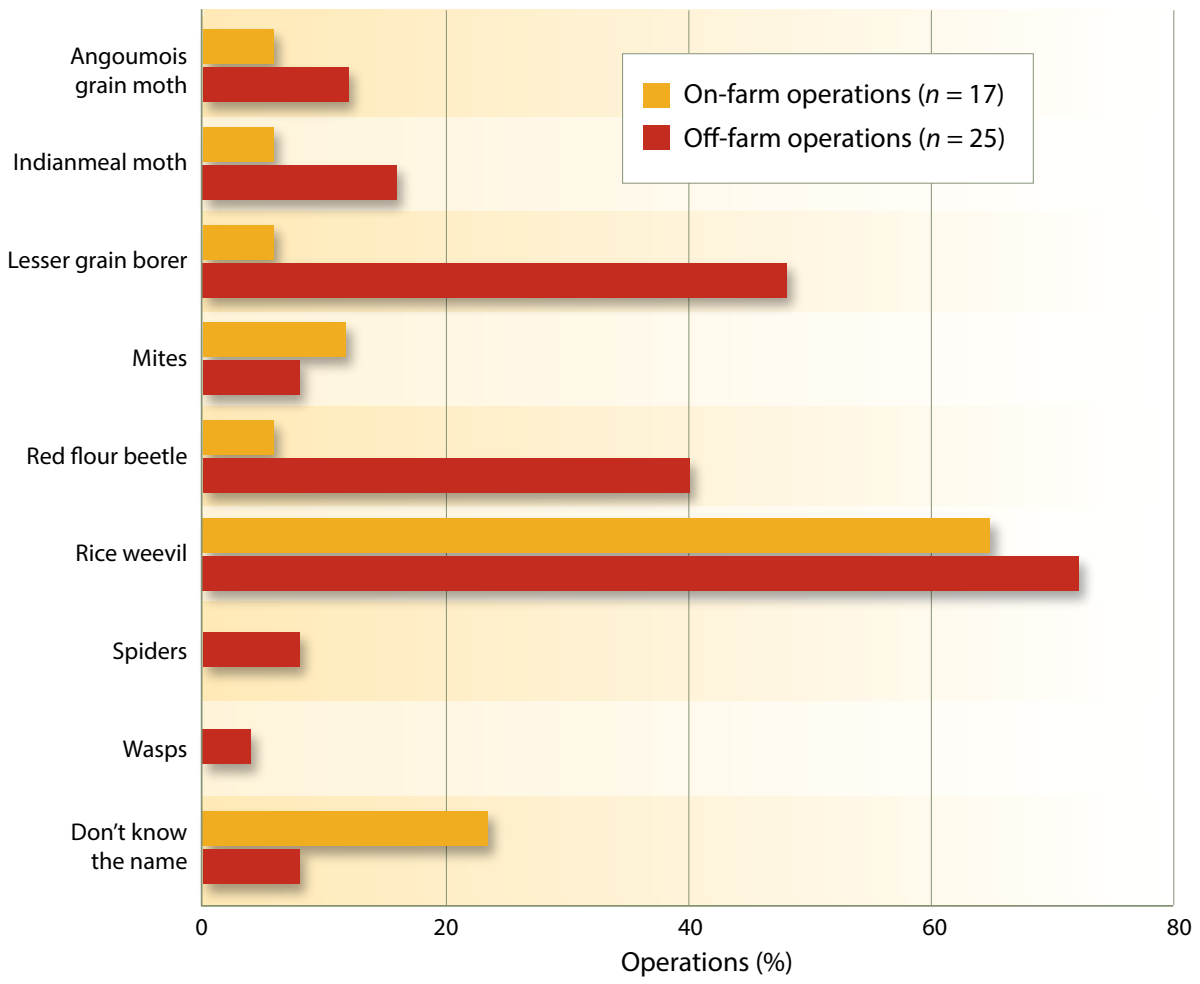

Fig. 2. Percentage of operations that named one of the following arthropods as causing problems in stored rough rice in the past 5 years: Angoumois grain moth, Sitotroga cerealella (Olivier); Indianmeal moth, Plodia interpunctella (Hübner); lesser grain borer, Rhyzopertha dominica (Fabricius); mites; red flour beetle, Tribolium castaneum (Herbst); rice weevil, Sitophilus oryzae (Linnaeus); spiders or wasps. Respondents were given the option to select "I don't know the name of the insects." important problems is insect infestation, followed by maintaining appropriate grain moisture and temperature.

Operations that chose insects as a problem were asked to name up to three insects that caused problems in the past 5 years; respondents could also select the option "I don't know the name of the insects." More than $60 \%$ of on-farm operations named the rice weevil, Sitophilus oryzae (Linnaeus), and more than $20 \%$ indicated that they did not know the name of the insects (fig. 2). More than $70 \%$ of off-farm operations named the rice weevil, and more than $40 \%$ named the lesser grain borer, Rhyzopertha dominica (Fabricius), and red flour beetle, Tribolium castaneum (Herbst). Only a small proportion of off-farm operations indicated not knowing the name of the insects.

When asked what actions are likely to be taken if insects become a problem during storage, the majority of operations selected fumigation (table 3). Aeration was the second most selected option. On-farm operations respondents who selected the "other" category explained that they had never had a problem with insects.

\section{Monitoring}

Stored rice should be inspected to determine its temperature, moisture content and sanitary condition throughout the storage period (Howell 2003). In our survey, almost all operations (97\%, $n=61)$ reported inspecting rice during storage. Only two on-farm operations reported not conducting inspections.

Stored-rice monitoring guidelines recommend that storage operators inspect

\begin{tabular}{|c|c|c|}
\hline Action & $\begin{array}{l}\text { On-farm } \\
\text { operations } \\
(n=31)\end{array}$ & $\begin{array}{c}\text { Off-farm } \\
\text { operations } \\
(n=29)\end{array}$ \\
\hline & \multicolumn{2}{|c|}{ 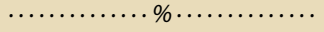 } \\
\hline Aerate grain & 22.6 & 37.9 \\
\hline $\begin{array}{l}\text { Spray surface of } \\
\text { grain mass }\end{array}$ & 3.2 & 0.0 \\
\hline $\begin{array}{l}\text { Spray area } \\
\text { around storage }\end{array}$ & 9.7 & 20.7 \\
\hline Fumigate grain & 90.3 & 96.6 \\
\hline $\mathrm{CO}_{2}$ treatment & 3.2 & 3.4 \\
\hline Heat treatment & 0.0 & 3.4 \\
\hline Other & 12.9 & 0.0 \\
\hline
\end{tabular}


rice twice a month when temperatures are below $60^{\circ} \mathrm{F}$ and weekly when temperatures are above $60^{\circ} \mathrm{F}$ (Mutters and Thompson 2009). In our survey, operators were asked how frequently they inspected their rice during winter and summer. For summer, half of on-farm operators selected "other" as their frequency of inspection (fig. 3). These operators explained that grain is usually taken out of storage before summer and therefore summer inspections were not conducted. Of those keeping rice during the summer months, inspections were made once a week, once every 2 weeks or once a month in very similar proportions. For winter, most onfarm operations reported inspecting their rice once a week or every 2 weeks. One on-farm operator selected "other" and explained that the operation only inspects rice after rainstorms.

For off-farm operations, the percentage of responses for each frequency of inspection was similar during summer and winter. Most off-farm operations reported inspecting rice once a week, followed by once every 2 weeks and once a month. Off-farm operations respondents who selected the "other" category explained that their storage time was very short, usually less than a week, and therefore they did not need to inspect grain frequently.

On-farm operations $(n=29)$ indicated that the most common methods of inspecting rice were looking at the surface of the grain mass $(72.4 \%)$, inspecting samples taken with a probe $(72.4 \%)$ and inspecting samples scooped from the surface of the grain mass (58.6\%). Off-farm operations $(n=28)$ reported inspecting the grain surface $(78.6 \%)$, using a grain probe $(75 \%)$ and using the temperature of the grain as an indicator of pest activity or spoilage in the grain (64.3\%). Most operations $(79.3 \%)$ used more than one method to inspect rice.

Of all respondents, two-thirds reported using a guideline or rule to determine if insects were a problem during storage, and significantly more off-farm operations than on-farm operations indicated doing so (table 4). These responses indicate that $50 \%$ of the on-farm operations and $20 \%$ of the off-farm operations replying to the survey rely instead on subjective measures or experience to determine when an insect infestation becomes a problem.
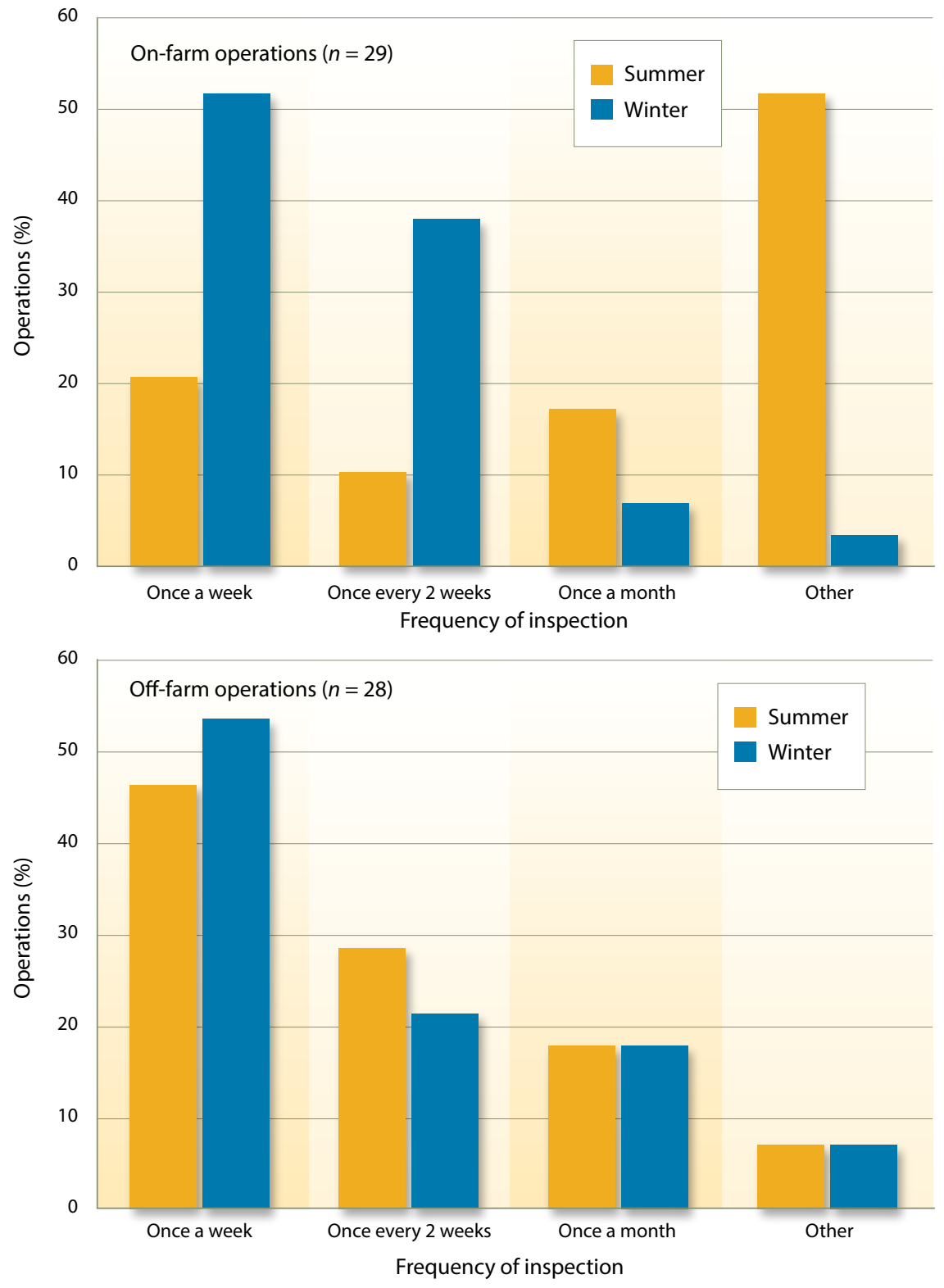

Fig. 3. Percentage of operations that indicated conducting inspections once a week, once every 2 weeks and once a month.

TABLE 4. Percentage of operations implementing pest management actions during the 2010-2011 storage period

\begin{tabular}{|c|c|c|c|}
\hline & On-farm operations & Off-farm operations & All \\
\hline & (1) & $\ldots \ldots \% \ldots \ldots$ & $\ldots \ldots$ \\
\hline Uses insect guideline* & $53.3(n=30)$ & $81.5(n=27)$ & 66.7 \\
\hline Uses insect traps* & $13.3(n=30)$ & $37.9(n=29)$ & 25.4 \\
\hline Monitors rice temperature & $76.7(n=30)$ & $85.7(n=28)$ & 81.0 \\
\hline Applies a fumigation treatment* & $26.7(n=30)$ & $89.7(n=29)$ & 57.6 \\
\hline $\begin{array}{l}\text { Treats structures with an insecticide } \\
\text { before filling them with grain }\end{array}$ & $73.3(n=30)$ & $79.3(n=29)$ & 76.3 \\
\hline $\begin{array}{l}\text { Applies an insecticide to the area } \\
\text { surrounding storage structures }\end{array}$ & $60.0(n=30)$ & $72.4(n=29)$ & 66.1 \\
\hline
\end{tabular}

* Significant differences between on- and off-farm operations, using chi-square test ( $a=0.05$ ). 
Insect trap use is recommended inside and around grain structures to detect the presence of damaging insects in or around the grain and determine their spatial and temporal distribution (Hagstrum 2000). Insect trap use was relatively uncommon among the operations that responded to the survey (table 4), with a significantly higher proportion of off-farm operations using insect traps than onfarm operations. The limited use of insect traps may be due to cost, time needed to install and service the traps and lack of skills to identify the trapped insects.

\section{Pest management practices}

Sanitation. Sanitation is the most costeffective way to manage storage pests (Cogburn 1980). The elimination of grain, dust and other residue where insects survive while storage structures are empty reduces the potential for infestation of newly stored grain. In our survey, a large proportion of operations $(93 \%, n=59)$ reported thoroughly cleaning their storage structures before storing new rice. However, almost $7 \%$ of respondents indicated not doing so. Although this proportion is low, it shows further improvement in the adoption of sanitation practices is possible. Emphasis on sanitation during training of operators may help increase adoption. A large proportion of operations indicated cleaning up spills and grain residue $(98 \%, n=59)$, vegetation and animal debris $(97 \%, n=59)$ around their storage structures.

Insecticide applications on the inside surfaces of storage structures kill insects that remain inside the structures while they are empty. This seems to be a common practice among both on- and off-farm operations (table 4). Spraying an insecticide in the area surrounding the storage structure if insects were found to be a problem during rice storage was a practice identified as likely to be implemented (table 3), and more than half of the survey respondents used insecticides in this way. Since areas around storage structures are sometimes treated on a calendar basis, the proportion of operations actually taking this action is higher than the proportion of operations that reported this as a likely action if an insect infestation was found (tables 3 and 4).

Aeration. A practice identified as likely to be implemented if insects were found to be a problem during rice storage was aeration (table 3 ). When rice reaches temperatures between $70^{\circ} \mathrm{F}$ and $90^{\circ} \mathrm{F}$, the risk of insect damage is increased (Mutters and Thompson 2009; Steffe et al. 1980). Managers can aerate to reduce grain temperature, thus reducing the likelihood of insect infestation. Also, by monitoring grain temperature, managers can find hot spots, areas where insect or microorganism activity causes the grain temperature to increase. The proportions of on- and off-farm operations that reported monitoring grain temperature during storage were similar (table 4). The proportion of operations that reported not monitoring temperature is close to $20 \%$.
Fumigations and insecticide use. A

large majority of on-farm operations identified fumigation as a likely action to be implemented if insects were found to be a problem during storage (table 3). During the 2010-2011 storage period, approximately one-quarter reported fumigating the grain (table 4). Most off-farm operations reported fumigation as an action to be taken if insects were found infesting grain (table 3) and, in fact, most reported fumigating some or all of their stored rice during the 2010-2011 storage period (table 4). The majority of these operations $(81 \%)$ reported that fumigation was conducted because insects were found during

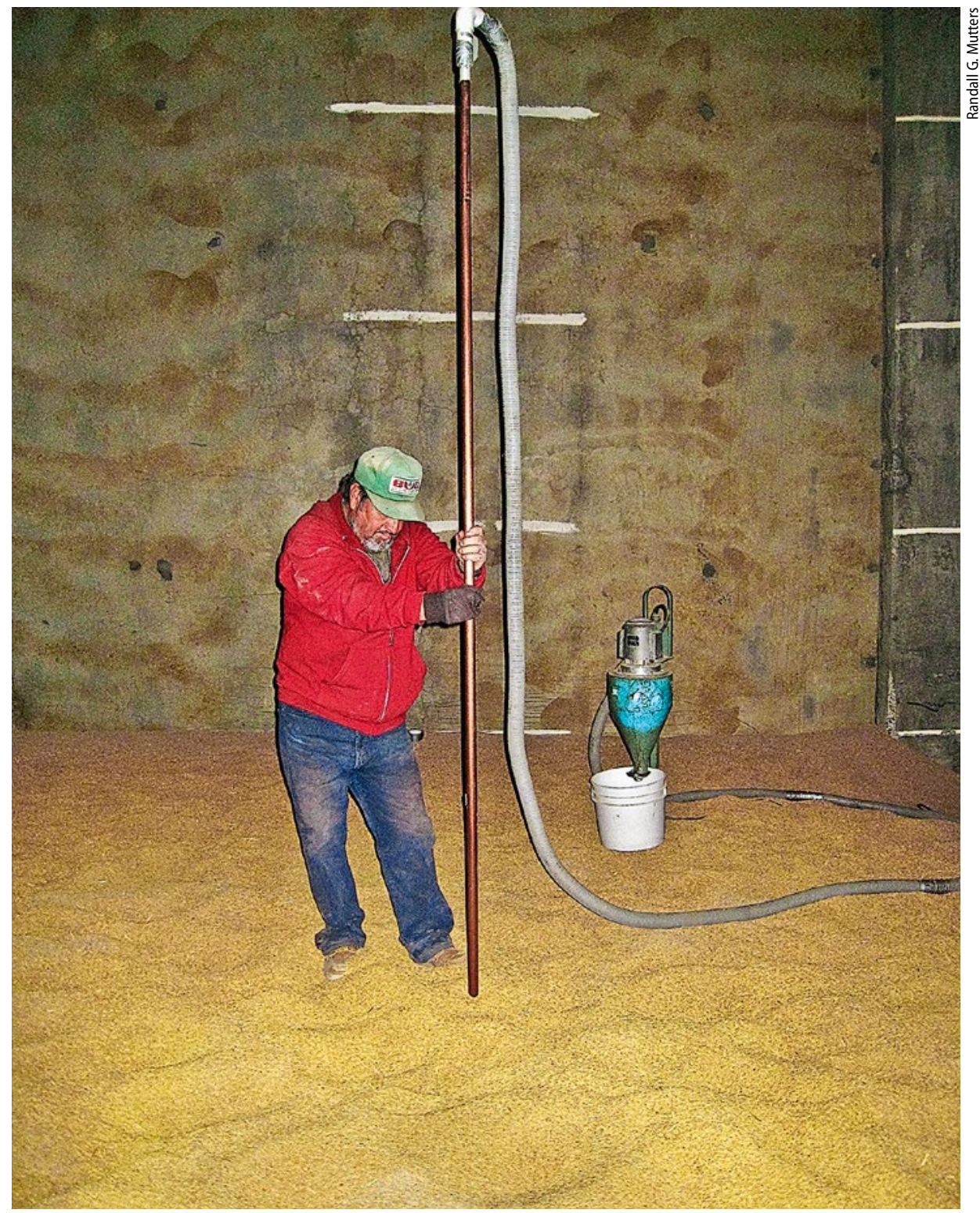

Stored rice should be inspected to determine its temperature, moisture content and sanitary condition throughout the storage period. In the authors' survey, almost all operations reported inspecting rice during storage. Above, a warehouse operator uses a grain probe to sample rice in a flat warehouse. 
sampling of stored rough rice. Only $15 \%$ of operations that fumigated grain indicated that fumigations are always conducted at some time during storage or before moving rice out of storage.

Proper and safe application of fumigants requires highly skilled operators (Cogburn 1985; Howell 2003). In
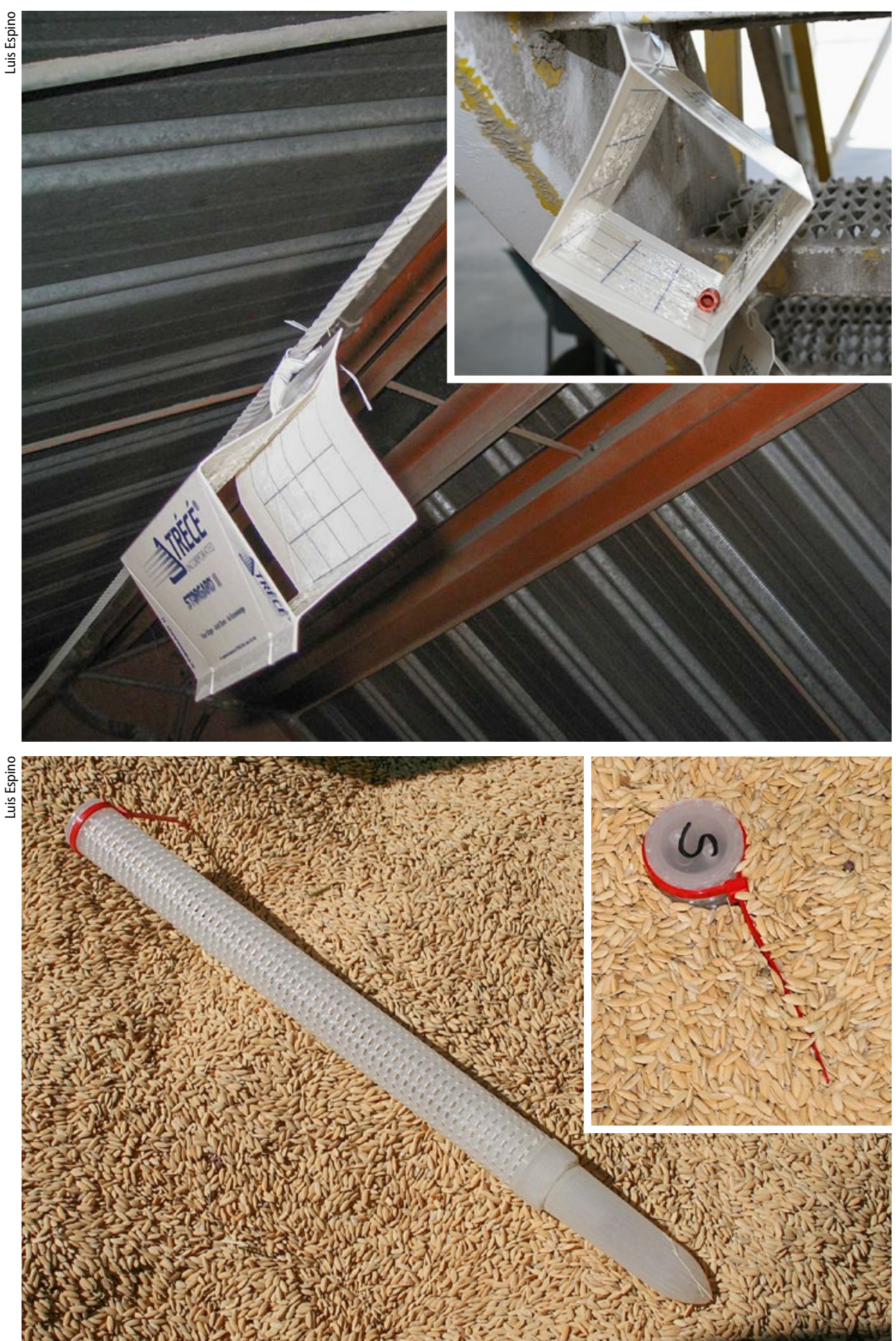

A fourth of the operations responding to the survey indicated using insect traps. Traps can be used to monitor insect populations and anticipate problems. Top, sticky trap with pheromone lure, inset, for capture of flying insects. Above, probe trap for capture of insects moving in the grain mass.
California, some operations use their own employees to conduct fumigations, while others hire commercial fumigation services. In our survey, $54.5 \%$ and $45.5 \%$ of operations that fumigated during the 2010-2011 storage period reported doing the fumigation themselves or hiring a commercial fumigation service, respectively. The cost of fumigation reported varied considerably. Eight on-farm operations reported costs that ranged from $\$ 550$ to $\$ 30,000$, with a mean of $\$ 6,255$ per operation, and 23 off-farm operations reported costs that ranged from $\$ 900$ to $\$ 133,020$, with a mean of $\$ 19,528$ per operation.

The use of insecticides as protectants (insecticide applications to grain as it is put into storage or to the top layer of the grain mass during storage) has been recommended to prevent insect infestations of stored rice (Cogburn 1985; Howell 2003). In our survey, none of the respondents indicated treating the grain with an insecticide as it is put into storage.

\section{Extension and research needs}

Several conclusions regarding grain and pest management can be drawn from the results of our survey. First, on- and off-farm operations face similar issues during rice storage. Keeping rice at the appropriate moisture content and temperature and free of insect infestations seem to be the most important challenges. Insects are perceived as a more important problem by off-farm operations. This is probably because off-farm operations store larger amounts of rice and are more likely to store rice during the summer, when conditions are more favorable for insect development.

Second, results show that most storage operations inspect grain during storage, monitor temperature, use insect thresholds, and conduct sanitation and aeration as means to manage storage problems. All these practices are part of an IPM program of stored grain, indicating that IPM adoption among storage facilities in the Sacramento Valley is high.

Third, fumigant use is relatively low among on-farm operations and high among off-farm operations. For both types of operation, managers are more inclined to respond to insect infestations with fumigants than with other management methods.

Several aspects of rice storage in California, including pest management, can be improved through Cooperative Extension activities directed at storage operations. Close to $20 \%$ of operations responding to the survey reported not monitoring the temperature of the grain during storage. Because grain temperature can affect the quality of the grain as 
well as the development of insect infestations, managers should be encouraged to include temperature monitoring in their programs. Our survey also showed that a large proportion of operations do not monitor rice during the summer months as frequently as it is recommended. Managers need to understand the effects of high temperature on insect populations and the importance of early detection of insect infestations. temperature and insect infestations. For example, insect traps could be used to facilitate insect monitoring, allowing managers to detect problems early, before deterioration occurs. Guidelines for their use in different storage structures could be developed. The use of insecticides as grain protectants should be explored. Also, alternative fumigants are needed. The 1991 Clean Air Act has reduced the use of methyl bromide, a

\section{Currently, research in stored-rice management in California is very limited. Our survey indicates that operations would benefit from research to improve management of grain moisture content, temperature and insect infestations.}

More than $20 \%$ of on-farm operations that recognized insects as a problem indicated that they did not know the name of the insects causing problems. Managers need to be trained in stored-rice insect identification so they can differentiate between arthropods that pose a threat to stored rice and those that are only incidental. Only a quarter of operations responding to our survey indicated that they use insect traps. The use of traps could be encouraged as an effective way to monitor insect populations. Although the use of insect thresholds is high among off-farm operations, only half of on-farm operations report using one. By promoting monitoring and insect identification, on-farm operations may be more likely to adopt insect guidelines.

Finally, slightly more than half of respondents reported conducting their own fumigation. Training on the safe handling and application of fumigants should be offered to these operations.

Since 2000, UC Cooperative Extension has organized the Rice Quality Workshop, a 1-day training session where storage managers are trained in best management practices to preserve grain quality. This workshop is highly popular among managers, and it is usually held at full capacity. Needs identified by our survey can be addressed by strengthening or incorporating content in the workshop.

Currently, research in stored-rice management in California is very limited. Our survey indicates that operations would benefit from research to improve management of grain moisture content, fumigant widely used in rice storage in the past (Cogburn 1985) that is now being phased out (Howell 2003). The registration of the fumigant sulforyl fluoride, a methyl bromide replacement, is currently being evaluated and may be cancelled (EPA 2011), leaving phosphine as the only fumigant available. The repeated use of a single control agent will undoubtedly lead to resistance in insect pests of stored rice. Other forms of insect control should be evaluated. Heat and $\mathrm{CO}_{2}$ treatments

\section{References}

Cogburn RR. 1980. Insect pests of stored rice. In: Luh BS (ed.). Rice: Production and Utilization. Westport, CT: AVI Publishing Company. p 289-310.

Cogburn RR. 1985. Rough rice storage. In: Juliano BO (ed.). Rice: Chemistry and Technology. St. Paul, MN: American Association of Cereal Chemists. p 265-88.

Dillman DA, Smyth JD, Christian LM. 2009. Internet, Mail, and Mixed-Mode Surveys. The Tailored Design Method. Hoboken, NJ: John Wiley \& Sons. p 499.

[DPR] California Department of Pesticide Regulation. 2011. Pesticide Use Report Data. www.cdpr.ca.gov/ docs/pur/purmain.htm.

Hagstrum DW. 2000. Using five sampling methods to measure insect distribution and abundance in bins stor ing wheat. J Stored Prod Res 36:253-62.

Hill JE, Williams JF, Mutters RG, Greer CA. 2006. The California rice cropping system: Agronomic and natural resource issues for long-term sustainability. Paddy Water Environ 4:13-9.

Howell TA. 2003. Rice storage. In: Smith CW, Dilday RH (eds.). Rice: Origin, History, Technology and Production. Hoboken, NJ: John Wiley \& Sons. p 545-66.

Kunze OR, Calderwood DL. 1985. Rough rice drying. In: Juliano BO (ed.). Rice: Chemistry and Technology. St. Paul, MN: American Association of Cereal Chemists. p 233-63. Mutters RG, Thompson JF. 2009. Rice Quality Handbook. UC ANR Pub 3514. Oakland, CA. p 141 are still uncommon (table 3) because of their high cost (Howell 2003). Similarly, infrared radiation is promising (Pan et al. 2008); however, the cost of implementation is still prohibitive. Research in these and other new forms of insect management is needed to make them cost effective.

L.A. Espino is UC Cooperative Extension Rice Farming Systems Advisor, Colusa, Glenn and Yolo Counties; C.A. Greer is UC Cooperative Extension Rice Farming Systems Advisor, Sutter-Yuba, Sacramento and Placer-Nevada Counties; R.G. Mutters is UC Cooperative Extension Farm Advisor, Butte County; and J.F. Thompson is Emeritus Specialist, Department of Biological and Agricultural Engineering, UC Davis. This research was funded by the Western IPM Center 2011 Competitive Grants Program. We thank the California Warehouse Association and county agricultural departments for suggesting contacts, reviewers of the draft questionnaire for their suggestions and survey respondents for their answers and comments.

Pan Z, Khir R, Godfrey L, et al. 2008. Feasibility of simultaneous rough rice drying and disinfestations by infrared radiation heating and rice milling quality. J Food Eng 84:469-79.

Steffe JF, Singh RP, Miller GE. 1980. Harvest, drying and storage of rough rice. In: Luh BS (ed.). Rice: Production and Utilization. Westport, CT: AVI Publishing Company. p 311-59.

[USDA FGIS] United States Department of Agriculture Federal Grain Inspection Service. 2002. United States Standards for Rice. USDA/Grain Inspection, Packers and Stockyards Administration/Federal Grain Inspection Service. www.gipsa.usda.gov/fgis/standards/ricestandards.pdf.

[USDA NASS] United States Department of Agriculture National Agricultural Statistics Service. 2012. Quick Stats. http://quickstats.nass.usda.gov/.

[US EPA] United States Environmental Protection Agency. 2011. Sulforyl Fluoride; Proposed Order Granting Objections to Tolerances and Denying Request for a Stay. Federal Register 76 (Jan. 19, 2011): 3422-49. 